\title{
Synaptic Potentials Mediated by $\alpha 7$ Nicotinic Acetylcholine Receptors in Supraoptic Nucleus
}

\author{
Glenn I. Hatton and Qin Zhao Yang \\ Department of Cell Biology and Neuroscience, University of California, Riverside, California 92521
}

Brain slice preparations preserving projections from nearby forebrain cholinergic neurons to the supraoptic nucleus (SON) were used to study synaptic potentials mediated by nicotinic acetylcholine receptors (nAChRs) in the hypothalamus. Pairedpulse electrical stimulation in an area anterior to the SON that was rich in cholinergic cells confirmed the monosynaptic nature of the connections to putative oxytocin and vasopressin SON neurons. With ionotropic glutamate and $\mathrm{GABA}_{\mathrm{A}}$ transmission blocked, this stimulation evoked fast, atropine-insensitive EPSPs that were sensitive to $\mathrm{nAChR}$ antagonists. Evoked EPSPs were blocked by methyllycaconitine and $\alpha$-bungarotoxin, antagonists that are selective for nAChRs containing the $\alpha 7$ subunit, but not by dihydro- $\beta$-erythroidine at concentrations known to antagonize $\alpha 4 \beta 2 \mathrm{nAChRs}$. Although anatomical evidence exists for postsynaptic $\alpha 4 \beta 2 \mathrm{nAChRs}$ in the SON, these results indicate that postsynaptic $\alpha 7 \mathrm{nAChRs}$ are primarily responsible for the cholinergically mediated EPSPs. Repetitive stimulation suggested partial desensitization of the receptors. With iono- tropic glutamate transmission blocked, inhibition of AChE increased spontaneous EPSP frequency and amplitude, suggesting spontaneous $\mathrm{ACh}$ release. ACh, nicotine, and choline (a selective $\alpha 7 \mathrm{nAChR}$ agonist) were effective in evoking action potentials and repetitive firing with synaptic transmission blocked by low $\mathrm{Ca}^{2+}$, high $\mathrm{Mg}^{2+}$ medium. These agonists were also effective in evoking the type of phasic bursts characteristic of vasopressin neurons, long thought to be completely dependent on activation of NMDA receptors (NMDARs). Because phasic bursting is $\mathrm{Ca}^{2+}$-dependent, the functional equivalence of $\alpha 7 \mathrm{nAChR}$ and NMDAR activation in this regard is likely attributable to their large $\mathrm{Ca}^{2+}$ fluxing capacities. This is the first demonstration that synaptically released ACh results in fast, $\alpha 7 \mathrm{nAChR}-$ mediated EPSPs in hypothalamic neurons.

Key words: $\alpha$-bungarotoxin; choline; intracellular recording; magnocellular neuroendocrine neurons; methyllycaconitine; nicotine
Nicotinic acetylcholine receptors (nAChRs) have been documented only recently at postsynaptic sites in the mammalian brain, and only in a few brain areas, including the hippocampus (Alkondon et al., 1998; Frazier et al., 1998) and the neocortex (Roerig et al., 1997). These discoveries have forced reconsideration of the previous widely held view that all brain nAChRs are presynaptic (Sargent, 1993). It is not surprising that the hippocampus and the neocortex would be first in this regard, because they have well-established sources of cholinergic inputs (e.g., the septum and the basal forebrain). However, regions with less well established sources of cholinergic afferents might be no less likely to use postsynaptic nAChRs to control their complex functions. One such area for which there is long-standing functional evidence for involvement of cholinergic influence is the magnocellular hypothalamo-neurohypophysial system, in particular the supraoptic nucleus (SON) portion of that system (Hatton, 1990).

SON neurons of mammals synthesize either oxytocin (OX) or vasopressin (VP) and project axons to terminate in the pituitary neural lobe. Release of one or both of these peptides into the pituitary circulation occurs under a variety of physiological conditions, including dehydration, parturition, and lactation. Such

\footnotetext{
Received July 16, 2001; revised Oct. 5, 2001; accepted Oct. 11, 2001.

This work was supported by National Institutes of Health Grants R01 NS09140 and R01 NS16942 from the National Institute of Neurological Disorders and Stroke. We thank B. Cohen, E. R. Gillard, and T. A. Ponzio for helpful comments on an earlier draft of the manuscript. We also thank J. Kitasako for technical assistance.

Correspondence should be addressed to Glenn I. Hatton, Department of Cell Biology and Neuroscience, University of California, Riverside, CA 92521. E-mail: glenn.hatton@ucr.edu.

Copyright (C) 2001 Society for Neuroscience $\quad 0270-6474 / 01 / 220029-09 \$ 15.00 / 0$
}

complex stimuli inevitably demand that peptide release, and therefore OX and VP neuronal excitability, be subject to multiple controls, both synaptic and nonsynaptic (Hatton, 1997, 1999). Acetylcholine (ACh) was among the earliest neurotransmitters implicated in the control of water loss because it produced antidiuresis, via VP release, when injected systemically or directly into the SON (Pickford, 1939, 1947; Milton and Paterson, 1974). Using explants of hypothalamus that included the SON and the neural lobe, Sladek and Joynt (1979) showed that blockade of nAChRs with compounds such as hexamethonium interfered with osmotic release of VP. Electrophysiological experiments (Hatton et al., 1983; Gribkoff et al., 1988) suggested that nAChRs mediated or modulated synaptic responses to stimulation in an area near the SON that contained cholinergic neurons (Mason et al., 1983). Although they implicated nAChRs, these results did not define their presynaptic versus postsynaptic location. A dearth of knowledge regarding the characteristics and diversity of brain $\mathrm{nAChRs}$ forced an interruption of research efforts in this important area.

The pioneering studies of Berg and colleagues (Jacob and Berg, 1983; Zhang et al., 1994), demonstrating the presence of $\alpha$-bungarotoxin-binding $\mathrm{nAChRs}$ at postsynaptic sites and suggesting that their rapid desensitization may have clouded the previous investigations, revived interest in pursuing this phenomenon in the SON. At present, there is ultrastructural immunocytochemical evidence for postsynaptic $\alpha 4$-containing nAChRs (Shioda et al., 1997), electrophysiological evidence that pharmacologically applied agonists activate postsynaptic $\alpha 7 \mathrm{nAChRs}$ (Zaninetti et al., 2000), and light microscopic evidence for 
$\alpha$-bungarotoxin and $\alpha 7$ antibody binding (Meeker et al., 1986; del Toro et al., 1994; Zaninetti et al., 2000). Our horizontal hypothalamic slice preparation keeps intact a cholinergic synaptic projection to the SON, allowing the first demonstration that synaptically released ACh results in fast EPSPs in SON neurons, and that these responses are blocked by $\alpha 7$-selective but not by $\alpha 4$-selective or glutamate receptor antagonists.

\section{MATERIALS AND METHODS}

Animals and procedures. Ninety-seven adult male Sprague Dawley rats (Holtzman, Madison, WI), 55-70 d of age, were housed three rats per cage with access to food and water ad libitum and kept on a $12 \mathrm{hr}$ light/dark cycle. At $\sim 4-5 \mathrm{hr}$ into the light portion of the cycle, the rats were decapitated without anesthesia. The brains were quickly removed, mounted cortex down on the stage of a vibratome, and cut in a horizontal plane to 300-400 $\mu \mathrm{m}$ thickness into room-temperature medium. Slices were then placed in either a static bath (Hatton et al., 1980) or a perifusion chamber (Hatton et al., 1983) for delivery of drugs and maintained at $34-36^{\circ} \mathrm{C}$ in a medium made up of $95 \% \mathrm{O}_{2}$ and $5 \% \mathrm{CO}_{2}$. Control medium composition was (in $\mathrm{mm}$ ): $\mathrm{NaCl} 126, \mathrm{NaH}_{2} \mathrm{PO}_{4} 1.3$, $\mathrm{NaHCO}_{3} 26, \mathrm{KCl} 5, \mathrm{CaCl}_{2} 2.4, \mathrm{MgSO}_{4} 1.3$, glucose 10 , and 3-[Nmorpholino]propanesulfonic acid buffer $5, \mathrm{pH}$ 7.4. The combination of this organic buffer and $\mathrm{NaHCO}_{3}$ has been found in previous studies to better stabilize the $\mathrm{pH}$ over prolonged recording sessions than does the use of the bicarbonate buffer alone. In most of the experiments, the bathing medium also contained $6 \mu \mathrm{M}$ 6-cyano-7-nitroquinoxaline-2,3dione (CNQX) and 20 or $50 \mu \mathrm{M}$ DL-2-amino-5-phosphonovaleric acid (DL-APV); in many cases, $20 \mu \mathrm{M}$ bicuculline methiodide (BIC) was also added. The noncompetitive NMDA antagonist MK801 (40 $\mu \mathrm{M})$ was also used. These concentrations have been shown in a host of studies to be effective in blocking, respectively, non-NMDA-, NMDA-, and $\mathrm{GABA}_{\mathrm{A}^{-}}$ mediated potentials and currents in the SON. A solution shown previously to block synaptic transmission without blocking $\mathrm{Na}^{+}$channels was used; it contained $9.3 \mathrm{mM} \mathrm{Mg}^{2+}$ and $0.05 \mathrm{mM} \mathrm{Ca}^{2+}$ but was otherwise the same as the standard medium. This medium has been shown to block the Schaffer collateral to CA1 synaptic transmission in hippocampal slices (Hatton, 1982).

Recording electrodes were glass micropipettes filled with $1 \mathrm{M} \mathrm{K}$ ace-

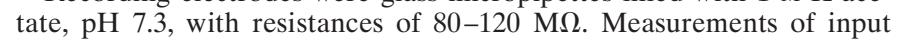
resistance were made by passing brief hyperpolarizing current pulses $(100-250 \mathrm{pA}, 100 \mathrm{msec})$ through the recording electrode at rates from 0.6 to $1 \mathrm{~Hz}$. Recordings were made using the bridge circuit of a Neurodata Dual Intracellular Amplifier (Neurodata, New York, NY). Resting potentials were determined at the times of both entering and exiting the cell. Only cells with resting membrane potentials more negative than -55 $\mathrm{mV}$ and overshooting action potentials were included in this study. Extracellular electrical stimulation was delivered through concentric bipolar electrodes (MCE 100; Rhodes Medical Instruments, Woodland Hills, CA) using constant current (50-250 $\mu \mathrm{A}, 0.1 \mathrm{msec})$. Our horizontal slices permitted placement of stimulating electrodes in an area anterior to the SON (Fig. 1) that was shown previously to be exceptionally rich in choline acetyltransferase-immunoreactive neurons (Mason et al., 1983).

The drugs used in the study were CNQX; DL-APV; MK801 (Tocris Cookson, Ballwin, MO); BIC; atropine sulfate (muscarinic blocker); D-tubocurarine chloride, hexamethonium bromide, and mecamylamine (three general nAChR antagonists); methyllycaconitine (MLA) and $\alpha$-bungarotoxin (antagonists selective for nAChRs containing the $\alpha 7$ subunit); dihydro- $\beta$-erythroidine (an antagonist selective for $\alpha 4 \beta 2$ $\mathrm{nAChRs}$ ), galanthamine, and tacrine (inhibitors of $\mathrm{AChE}$ ); and nicotine, choline, and ACh. Except for MK801, all compounds were purchased from Sigma (St. Louis, MO).

\section{RESULTS}

\section{Neuronal characteristics}

A total of 109 SON neurons recorded from 97 male rats met the criterion of being activated by electrical stimulation in the area rich in cholinergic neurons (Fig. 1). The membrane characteristics of these SON neurons were as follows (means \pm SEM for each measure): resting membrane potentials, $-58 \pm 2 \mathrm{mV}$; action potentials, $64 \pm 2 \mathrm{mV}$; and input resistances, $139 \pm 7 \mathrm{M} \Omega$. These are similar to those reported in the literature for SON neurons.

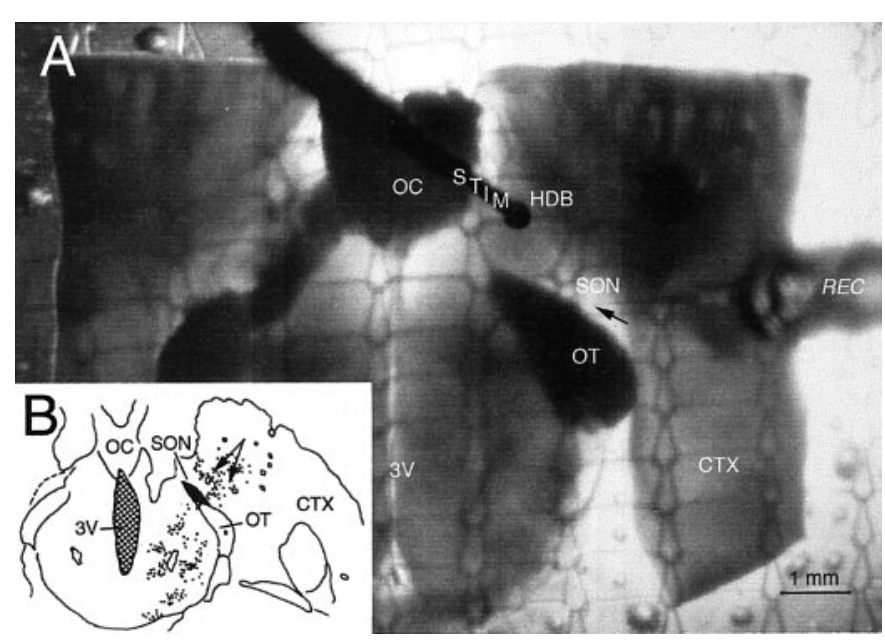

Figure 1. A, Micrograph of a transilluminated hypothalamic slice in a static recording chamber, showing the plane of the horizontal slice preparation used. $C T X$, Cortex; $H D B$, horizontal limb of the diagonal band of Broca; $O C$, optic chiasm; $O T$, optic tract; $R E C$, recording electrode (tip indicated by arrow); STIM, stimulating electrode; SON, supraoptic nucleus pars anterior; $3 \mathrm{~V}$, third ventricle. $B$, Diagram of horizontal section on which cholinergic neurons near the SON are plotted. (Modified from Mason et al., 1983.) Arrows indicate the area stimulated in this study.

\section{Paired pulse stimulation Repetitive stimulation}

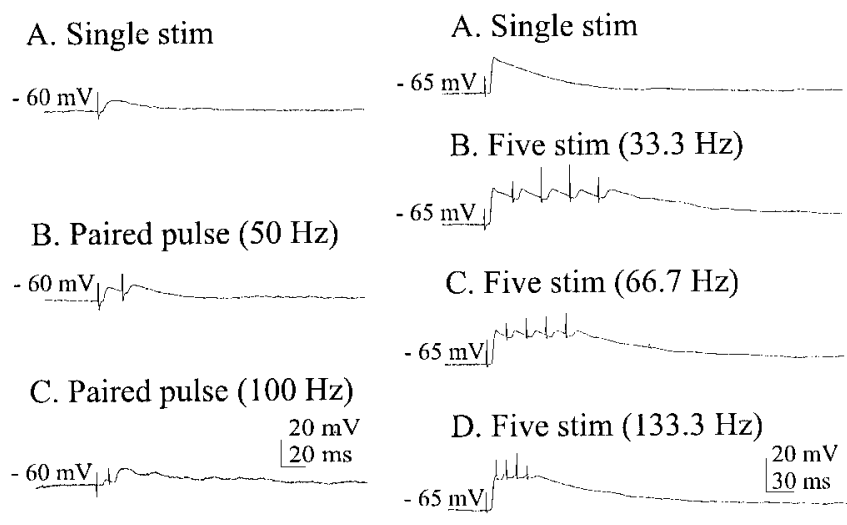

Figure 2. Recordings (averages of five traces) of two cells maintained in medium containing (in $\mu \mathrm{M}$ ): $6 \mathrm{CNQX}, 50$ DL-APV, and 20 BIC. Left, Synaptic responses to single- and paired-pulse stimulation of a cholinergic cell area. Right, Synaptic responses to repetitive stimulation of the same area. Cells subjected to repetitive stimulation were hyperpolarized by $2-5 \mathrm{mV}$.

\section{Synaptic responses}

Figure 2 shows typical ( $n=10$ cells) postsynaptic responses of two SON neurons to extracellular electrical stimulation in the cholinergic cell area. These traces were recorded in the presence of $6 \mu \mathrm{M}$ CNQX, $50 \mu \mathrm{M}$ DL-APV, and $20 \mu \mathrm{M}$ BIC, thus eliminating or strongly reducing the possibility that recorded EPSPs were mediated by glutamate. EPSPs were evoked by single, paired, and repetitive stimulation. Cells followed paired-pulse frequencies of 50 and $100 \mathrm{~Hz}$ (Fig. 2B,C, left), indicating that these connections are probably monosynaptic. Repetitive stimulation frequencies of $\geq 33.33 \mathrm{~Hz}$ were relatively tetanizing in maintaining the membrane potential in a depolarized state (Fig. $2 B-D$, right). The spontaneous activity of phasic (putative VP) SON neurons was generally eliminated by medium containing glutamate receptor 

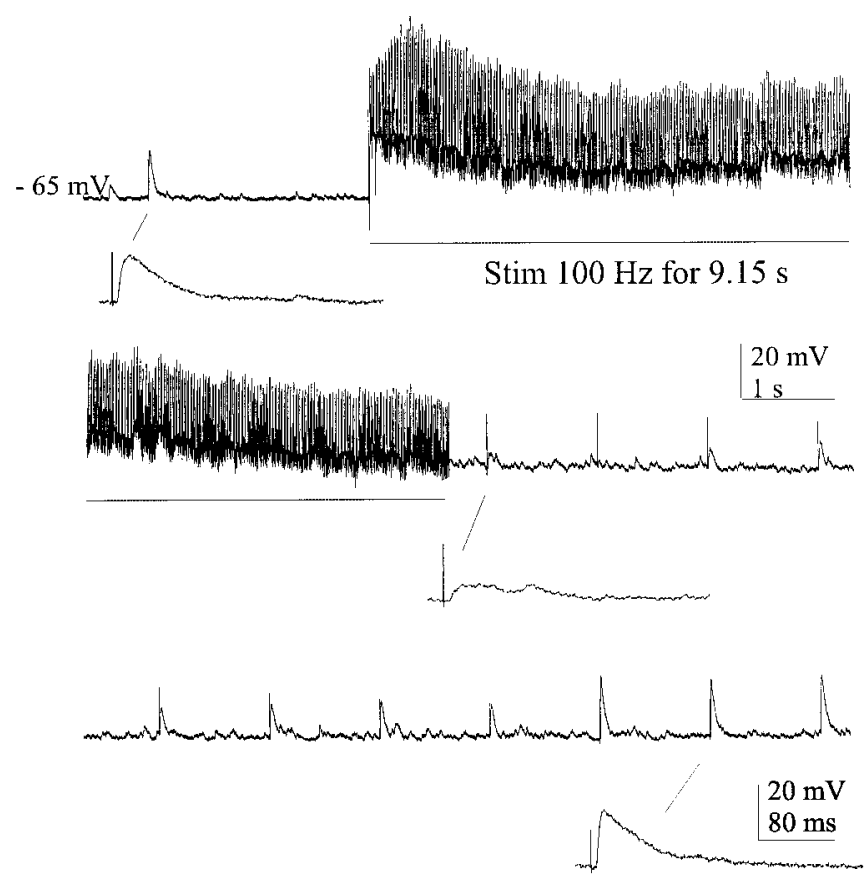

Figure 3. Continuous recording showing synaptic responses to single and high-frequency repetitive stimulation of a cholinergic cell area in medium containing (in $\mu \mathrm{M}$ ): $6 \mathrm{CNQX}, 50 \mathrm{DL}-\mathrm{APV}$, and $20 \mathrm{BIC}$. Indicated EPSPs are shown at higher sweep speed (insets below each trace). Subsequent single stimuli evoked attenuated EPSPs, which then recovered to amplitudes at or above those seen before stimulation. Cells were hyperpolarized by $5 \mathrm{mV}$ from the resting state to enhance EPSP amplitude.

antagonists, as reported previously (Hu and Bourque, 1992). In three of three such cells tested in this manner, stimulation of the cholinergic cell area was able to evoke single prolonged bursts of firing (data not shown). Similar stimulation occurring after the initial burst, when phasic cells would normally tend to be refractory to burst firing, required several evoked EPSPs before the occurrence of another prolonged burst. In this case, the refractoriness may result partially from receptor desensitization. Nonphasic (in many cases probably OX) cells also responded to this stimulation with EPSPs (see Fig. 5B).

In another three cells that were hyperpolarized $(2-5 \mathrm{mV})$ from resting potential, several seconds of high-frequency activation of the cholinergic inputs resulted in maintained depolarizations that declined in amplitude over time (Fig. 3, top and middle). Cessation of repetitive stimulation was followed by a period $(\sim 6-8 \mathrm{sec})$ of marked reduction in the size of the evoked EPSPs (Fig. 3, middle), which then recovered (Fig. 3, bottom). In these neurons, the EPSPs that were evoked several seconds after recovery had enhanced amplitudes compared with those before the highfrequency stimulation (Fig. 3, bottom right). A paired $t$ test analysis of EPSP amplitudes for the three cells tested in this manner showed that these changes were consistent across neurons. Mean EPSP amplitudes were $18.7 \mathrm{mV}$ (range, 17-20 mV) before stimulation; $8.0 \mathrm{mV}$ (range, $5-10 \mathrm{mV}$ ) at $1 \mathrm{sec}$ after stimulation $(p<$ 0.01 compared with before stimulation); and $24.7 \mathrm{mV}$ (range, $21-27 \mathrm{mV})$ at $10 \mathrm{sec}$ after stimulation $(p<0.03$ compared with before stimulation).

The decline in response to repetitive stimulation may indicate $\alpha 7$-receptor desensitization or depletion of transmitter in the presynaptic terminal. That the decline is incomplete may represent continued activation of the $\alpha 4 \beta 2$ receptor, which appears to be coexpressed on SON neurons and which may be otherwise masked by $\alpha 7$-receptor activation. Recovery occurs with the possibility of at least short-term potentiation of this nAChRmediated response. Using this paradigm, we found no evidence for long-term potentiation when test stimuli were applied after several minutes (data not shown).

\section{Effects of general AChR antagonists}

That these fast synaptic responses evoked by stimulation in the cholinergic cell group were likely to be mediated by nAChRs was tested in medium containing $6 \mu \mathrm{M}$ CNQX and $20 \mu \mathrm{M}$ DL-APV. In five of five cells tested, the evoked EPSPs were unaffected by adding $50 \mu \mathrm{M}$ atropine sulfate to the bath but were abolished in the presence of the nonselective nicotinic receptor antagonist hexamethonium bromide (data not shown). Washout of the antagonist restored the stimulus-evoked EPSPs. In another four cells, the stimulus-evoked EPSPs were reversibly eliminated by bath application of $20 \mu \mathrm{M}$ D-tubocurarine chloride (data not shown).

A dose-response relationship for blockade of the stimulusevoked EPSPs was established for a third general nAChR antagonist, mecamylamine. Five cells were tested with this compound. In control medium containing CNQX, DL-APV, and BIC, mecamylamine was ineffective at $5 \mu \mathrm{M}$, partially blocked the evoked EPSPs at $10 \mu \mathrm{M}$, and provided complete antagonism at 20 $\mu \mathrm{M}$ (data not shown). Blockade was reversed during washout. Such results implicate nAChRs as mediators of these synaptic potentials but provide no clues as to the identity of the receptor subtype involved.

\section{Effects of selective $n A C h R$ antagonists}

To determine the receptor subtype(s) mediating these responses, a series of experiments was performed using a variety of antagonists at different concentrations. At concentrations of $\sim 1 \mu \mathrm{M}$, dihydro- $\beta$-erythroidine is a selective antagonist at the $\alpha 4 \beta 2$ nAChR subtype (Alkondon and Albuquerque, 1993; Buisson et al., 1996). In medium containing CNQX and DL-APV, $1 \mu \mathrm{M}$ dihydro- $\beta$-erythroidine was ineffective in blocking the evoked EPSPs in five of five cells tested (Fig. 4A,B). However, these synaptic responses were reversibly abolished by the less selective, 10 -fold higher concentration of dihydro- $\beta$-erythroidine (Fig. $4 C, D)$.

MLA and $\alpha$-bungarotoxin are two generally available antagonists that are highly selective for the homomeric $\alpha 7$ nAChRs. Currents mediated by $\alpha 7 \mathrm{nAChRs}$ are generally abolished by concentrations of MLA in the nanomolar range (Alkondon and Albuquerque, 1993). We tested the ability of this antagonist to eliminate the cholinergically mediated EPSPs in both phasically and nonphasically firing SON neurons (Fig. $5 A, B$ ). Voltage traces in Figure $5 A 1-A 3$ are from a cell that exhibited spontaneous phasic firing in control medium, activity that was silenced in medium containing (in $\mu \mathrm{M}$ ): $20 \mathrm{BIC}, 6 \mathrm{CNQX}$, and $50 \mathrm{DL}-\mathrm{APV}$ (data not shown). This cell was hyperpolarized by $2 \mathrm{mV}$ to suppress occasional spontaneous spikes. EPSPs evoked by stimulation of the cholinergic cell area were effectively and reversibly eliminated by 5 nм MLA (Fig. 5A1-A3) in the cell shown and in the four other cells tested. Effective blocking concentrations of MLA in all cells tested (both phasic and nonphasic) ranged from 5 to $20 \mathrm{~nm}$.

A nonphasic or continuous pattern of firing (putative $\mathrm{OX}$ ) of a neuron recorded in control medium is shown in Figure $5 B$. Such patterns were incompletely silenced in medium containing (in 


\section{A. Control medium with CNQX \& APV}

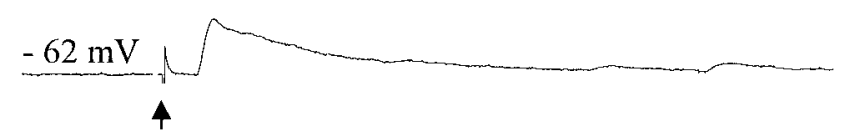

B. Medium with $1 \mu \mathrm{M}$ dihdro- $\beta$-erythroidine

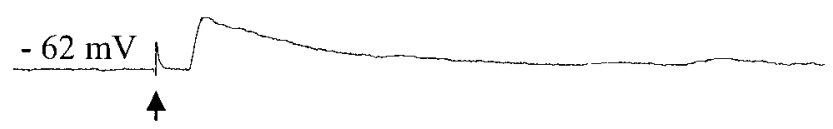

C. Medium with $10 \mu \mathrm{M}$ dihydro- $\beta$-erythroidine

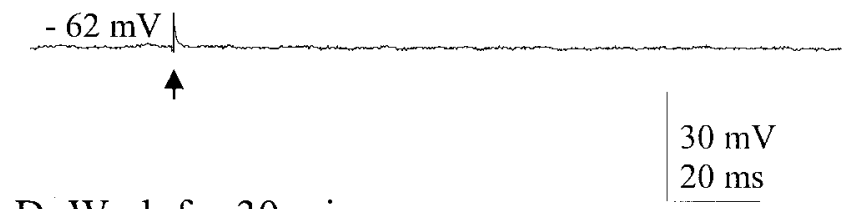

\section{Wash for $30 \mathrm{~min}$}

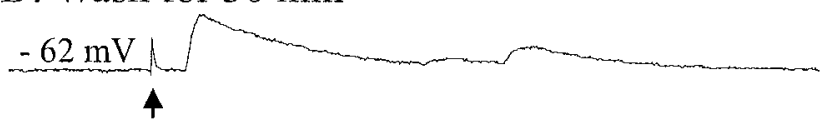

Figure 4. Synaptic responses to cholinergic cell stimulation (averages of five traces). Medium contained $6 \mu \mathrm{M}$ CNQX and $50 \mu \mathrm{M}$ DL-APV. Responses were blocked by $10 \mu \mathrm{M}$ but not $1 \mu \mathrm{M}$ dihydro- $\beta$-erythroidine, which is an $\alpha 4 \beta 2 \mathrm{nAChR}$-selective antagonist at concentrations up to $1 \mu \mathrm{M}$. Arrows indicate stimulus artifacts.
A. Phasically firing neuron

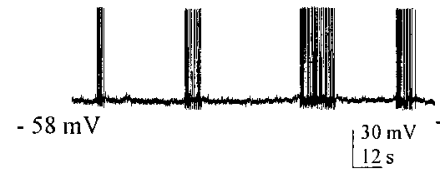
$\mathrm{CNQX} \& \mathrm{APV}$

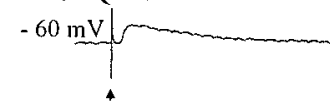

A2. Medium with $5 \mathrm{nM}$ MLA

$-60 \mathrm{mV}$

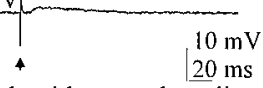

A3. Wash with control medium for $18 \mathrm{~min}$

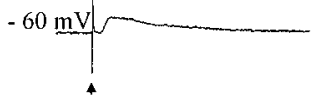

A1. Control medium with BIC,

\section{B. Continuously firing neuron}

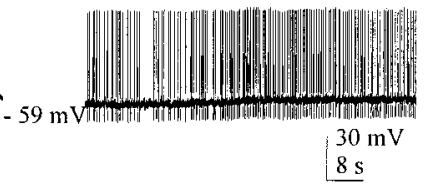

B1. Control medium with BIC, CNQX \& APV

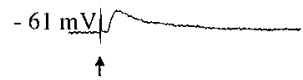

B2. Medium with $20 \mathrm{nM}$

MLA

$-61 \mathrm{mV}$ $\uparrow$

B3. Wash with control medium for $20 \mathrm{~min} \quad 10 \mathrm{mV}$ $-61 \mathrm{mV} / 20 \mathrm{~ms}$
Figure 5. Reversible blockade of cholinergically mediated synaptic responses in SON neurons with initial spontaneous firing patterns that were either phasic $(A)$ or continuous $(B)$ by the $\alpha 7 \mathrm{nAChR}$-selective antagonist MLA. MLA added to the medium in $A 1$ or $B 1$ reversibly abolished the synaptic responses in both cell types. Arrows indicate stimulus artifacts.

$\mu \mathrm{M})$ : 6 CNQX, 20 DL-APV, and 20 BIC (data not shown). Spontaneous firing was suppressed by $2 \mathrm{mV}$ of hyperpolarization. Reversible blockade of stimulus-evoked, cholinergically mediated responses in this medium is shown in Figure $5 B 1-B 3(n=5)$. Evoked EPSPs were blocked by the addition of MLA (20 nM) and restored by washout with glutamate receptor-blocking medium (Fig. 5B2,B3). Thus, both cell types in the SON displayed EPSPs

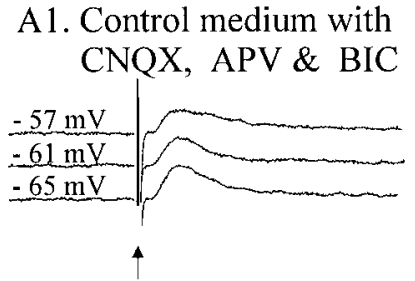

A2. MLA $(50 \mathrm{nM}), 5 \mathrm{~min}$

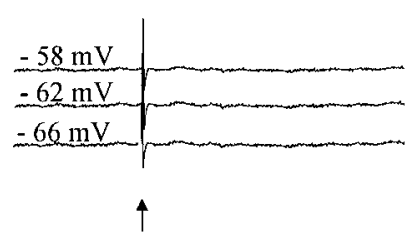

A3. Washout for $15 \mathrm{~min}$

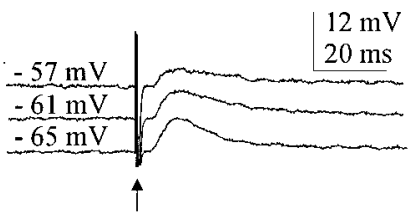

B1. Control medium with CNQX \& APV $-61 \mathrm{mV} / \mathrm{r}$ $\uparrow$

B2. High $\mathrm{Mg}^{2+}$, low $\mathrm{Ca}^{2+}$ $-61 \mathrm{mV}$

B3. Washout with control medium

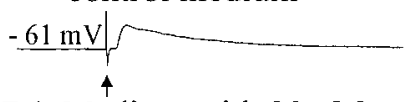

B4. Medium with $20 \mathrm{nM}$ $\alpha$-bungarotoxin, $4 \mathrm{~min}$ $-61 \mathrm{mV}$

B5. Medium with $100 \mathrm{nM}$ $\alpha$-bungarotoxin, $3 \mathrm{~min}$

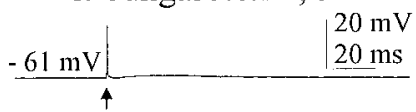

Figure 6. Blockade of synaptic responses in two different cells with $\alpha 7$-selective antagonists. A1, Cholinergic synaptic responses at resting and hyperpolarized potentials remained in the presence of $6 \mu \mathrm{M}$ CNQX, 50 $\mu \mathrm{M}$ DL-APV, and $20 \mu \mathrm{M}$ BIC. $A 2, A 3$, Recordings at hyperpolarized potentials show that these responses were completely and reversibly blocked by $50 \mathrm{~nm}$ MLA. B1, Synaptic responses that remained when glutamate transmission was blocked were reversibly eliminated by medium containing $9 \mathrm{mM} \mathrm{Mg}^{2+}$ and $0.05 \mathrm{mM} \mathrm{Ca}^{2+}(B 2, B 3)$. Synaptic responses were partially $(B 4)$ and then completely (B5) antagonized by 20 and $100 \mathrm{~nm} \alpha$-bungarotoxin. All records are the averages of five traces, with five cells in each treatment. Arrows indicate stimulus artifacts.

mediated by nAChRs that could be blocked by MLA in the low nanomolar concentration range. To be certain that MLA was effective in eliminating rather than just reducing the evoked responses, the EPSPs of several cells were enhanced by hyperpolarization of the membrane potential by up to $8 \mathrm{mV}$. MLA (50 nM) completely and reversibly abolished the EPSPs (Fig. $6 A 1-A 3)$.

Although its irreversibility makes it a less than perfect antagonist to work with, $\alpha$-bungarotoxin is the sine qua non for demonstrating $\alpha 7$ nAChRs. In five of five cells tested, $\alpha$-bungarotoxin (50-100 nM) abolished the EPSPs evoked by stimulation in the cholinergic cell-rich area (Fig. 6B). In medium containing drug concentrations that block NMDA and nonNMDA glutamate receptors, the responses to stimulation of the cholinergic cell group were intact but were abolished when synaptic transmission was blocked by a medium containing high $\mathrm{Mg}^{2+}$ and low $\mathrm{Ca}^{2+}$ (Fig. 6B1,B2). After washout with the blocking control medium (Fig. 6B3) had restored the synaptic responses, two concentrations of $\alpha$-bungarotoxin were applied sequentially; the higher concentration was effective in abolishing the EPSPs (Fig. 6B3-B5). This result shows that, in these cells, $\alpha$-bungarotoxin blocks the postsynaptic response to ACh release.

\section{Inhibition of $A C h E$}

Inhibition of the exquisitely rapid metabolism of ACh by $\mathrm{AChE}$ was done to assess the effects of AChE inhibition on spontaneously occurring and evoked EPSPs. Spontaneous EPSPs, most if not all of which were probably ACh-mediated, were readily ob- 
A. Control medium with $6 \mu \mathrm{M} \mathrm{CNQX}$, $50 \mu \mathrm{M}$ APV \& $20 \mu \mathrm{M}$ BIC

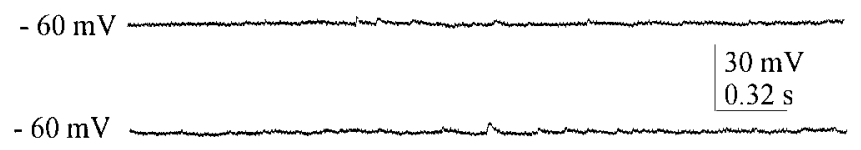

B. Medium with $20 \mu \mathrm{M}$ galanthamine for $3 \mathrm{~min}$
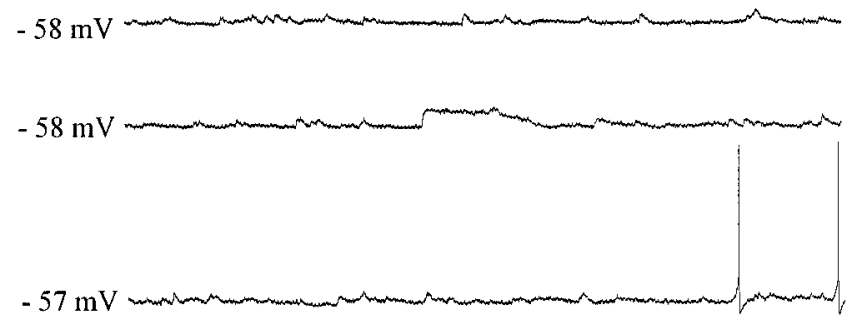

C. Washout for $20 \mathrm{~min}$

$-60 \mathrm{mV}$ -

$-60 \mathrm{mV}$ -

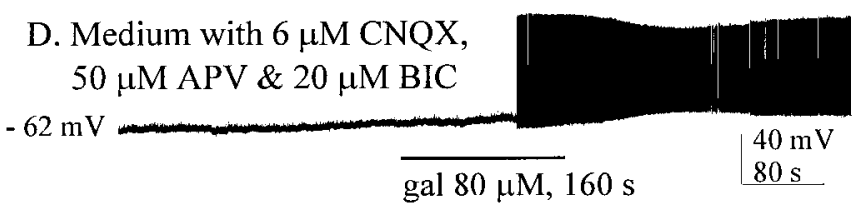

Figure 7. Effects of AChE inhibition by galanthamine. $A$, Spontaneous EPSPs were observable with ionotropic glutamate and $\mathrm{GABA}_{\mathrm{A}}$ receptors blocked. $B$, Addition of galanthamine resulted in a doubling of EPSP frequency and depolarization. $C$, Washout with the medium used in $A$ reduced EPSP frequency $(n=3)$. $D$, At higher concentrations (different cell), galanthamine induced larger depolarizations and prolonged excitability $(n=3)$.

servable in our glutamate- $\mathrm{GABA}_{\mathrm{A}}$ receptor-blocking medium (Fig. $7 A$ ). Inhibition of $\mathrm{AChE}$ by $20 \mu \mathrm{M}$ galanthamine produced an increase in the EPSP frequency in three of three cells tested. In the control medium blocking glutamate and $\mathrm{GABA}_{\mathrm{A}}$ receptors, mean EPSP frequency for these three cells was $2.73 / \mathrm{sec}$, more than doubling to $7.72 / \mathrm{sec}$ when galanthamine was added, as shown in Figure $7 B$. Washout with the blocking control medium returned the EPSP frequency to the control value (Fig. 7C). At higher concentrations, galanthamine application resulted in profound and prolonged increases in excitability (Fig. 7D), here seen in a different cell that was hyperpolarized to suppress spontaneous firing. Rising phase and amplitudes, but not the decay times of EPSPs evoked by stimulation of the cholinergic cell group, were enhanced in medium containing $20 \mu \mathrm{M}$ galanthamine (Fig. $8 A)$ in all eight cells tested in this manner. Similar results were obtained using another AChE inhibitor, tacrine $(n=3$, data not shown). These findings suggest that more transmitter was arriving at the receptor, as would be expected during the inhibition of AChE, although it is not possible here to rule out a direct effect of these inhibitors on the $\alpha 7$ receptors. In three cells, we observed similar effects on EPSP enhancement in response to $1 \mathrm{~mm}$ choline (Fig. $8 B$ ), effects that were blocked by MLA. These results are consistent with previous work showing that choline at this concentration acts as a selective agonist at $\alpha 7$ receptors (Alkondon et al., 1999) and as an inhibitor of AChE (Boyle et al., 1997; Stojan et al., 1999).

\section{A. Control medium with CNQX, APV \& BIC}

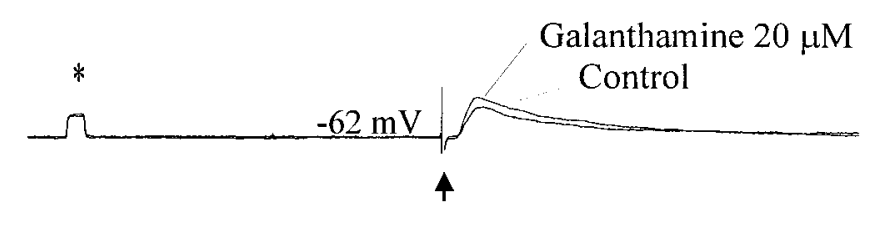

\section{B. Control medium with CNQX, APV \& BIC}

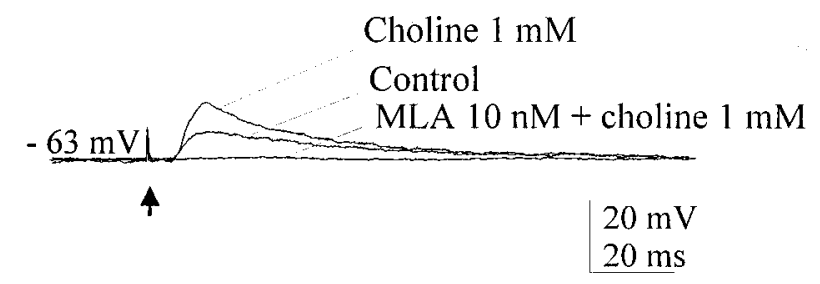

Figure 8. Enhancement of cholinergic EPSPs by AChE inhibition. $A$, Addition of galanthamine to the medium resulted in larger amplitudes and faster rising phases of evoked EPSPs. $B$, Similar enhancements were seen with $1 \mathrm{~mm}$ choline, which also may inhibit AChE (see Results). That choline EPSPs are $\alpha 7$-mediated is suggested by their blockade with MLA. Averages of five traces are shown; $n=3$ in each treatment. *Calibration pulse in $A, 10 \mathrm{mV}, 5 \mathrm{msec}$. Arrows indicate stimulus artifacts.

We also confirmed the blockade of the NMDARs by our glutamate-GABA $\mathrm{A}$-receptor blocking medium by substituting the noncompetitive antagonist MK801 $(40 \mu \mathrm{M})$ for DL-APV $(n=3)$. In this medium, as in the one containing DL-APV, synaptic responses to stimulation of the cholinergic cell group were evoked and were blocked by $20 \mathrm{~nm}$ MLA (data not shown).

\section{Agonist effects on SON neurons}

\section{Acetylcholine}

Both phasic and nonphasic types of SON neurons responded to bath applications of ACh with excitation (Fig. 9A-C). In control medium containing no antagonists (Fig. 9A,B), bath application of ACh depolarized by several millivolts and enhanced the firing rate of cells that had been firing continuously for several minutes before treatment (Fig. 9A). This cell, and others treated similarly, slowly returned to the control firing rate. Phasically firing cells (Fig. 9B) often showed larger depolarizations and an enhancement of fluctuations in membrane potential in response to ACh. However, we did not systematically study these effects on the cells exhibiting the two firing patterns. To further establish these responses to $\mathrm{ACh}$ as being attributable to activation of postsynaptic nAChRs, ACh application was performed in high $\mathrm{Mg}^{2+}(9.3$ $\mathrm{mm})$, low $\mathrm{Ca}^{2+}(0.05 \mathrm{~mm})$ medium $(n=3)$. ACh was effective in inducing excitation in all three neurons treated in this manner. Figure $9 C$ shows the response of a continuously firing neuron to $\mathrm{ACh}$ application in the absence of normal synaptic activity. As is typical for such neurons, this medium tends to stabilize the membrane potential, allowing a somewhat smaller membrane depolarization in response to $\mathrm{ACh}$ than in control medium (compare Fig. 9A).

\section{Nicotine}

Responses of cells to nicotine, applied by either bath or nanodrop to the surface of the slice, revealed a general sensitivity to 
A. Continuously firing cell

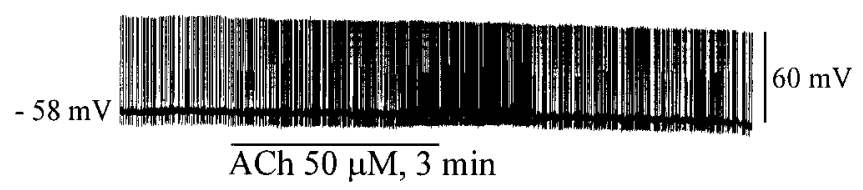

B. Phasically firing cell

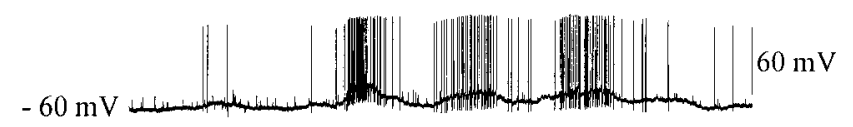

$\overline{\mathrm{ACh}} 20 \mu \mathrm{M}, 50 \mathrm{~s}$

C. In high $\mathrm{Mg}^{2+} \&$ low $\mathrm{Ca}^{2+}$ medium

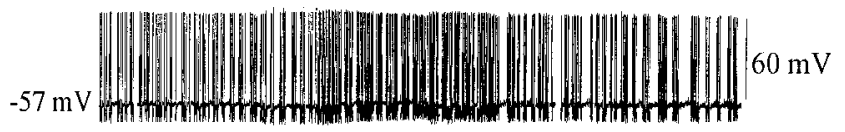

$\overline{\mathrm{ACh}} 50 \mu \mathrm{M}, 15 \mathrm{~s}$

Figure 9. Effects of $\mathrm{ACh}$ on $\mathrm{SON}$ neurons showing two spontaneous firing patterns. $A$, ACh application increased the firing rates of continuously firing cells with slight membrane depolarization $(n=5)$. $B$, Firing of phasic cells was increased by ACh application, which usually also led to membrane potential oscillations $(n=5)$. $C$, The postsynaptic site of ACh action is suggested by its efficacy with synaptic transmission blocked $(n=3)$.

nicotine in SON neurons. For four cells tested with bath applications of nicotine at relatively low concentrations $(5-20 \mu \mathrm{M})$, the minimal effective dose was $10 \mu \mathrm{M}$ (data not shown). At the higher concentrations tested on phasic neurons in control medium, nicotine tended to produce prolonged bursts superimposed on plateau potentials. This is seen in a cell that spontaneously displayed classic phasic activity (Fig. $10 A-C$ ). Nicotine at 10 and $20 \mu \mathrm{M}$ but not at $5 \mu \mathrm{M}$ prolonged burst lengths for several minutes after bath application. High $\mathrm{Mg}^{2+}$, low $\mathrm{Ca}^{2+}$ blockade of synaptic transmission did not interfere with the enhancement of neuronal excitability by nicotine (Fig. 10C,D).

\section{Choline}

A main metabolite of $\mathrm{ACh}$, choline has been shown to be an agonist at $\alpha 7$ nAChRs (Papke et al., 1996; Alkondon et al., 1997). Typically, spontaneous phasic firing of VP neurons is eliminated by the blockade of glutamate transmission, in particular that attributable to NMDARs (Hu and Bourque, 1992). This is because plateau potentials and phasic firing are generated by $\mathrm{Ca}^{2+}$ dependent depolarizing afterpotentials (Bourque, 1986; Li et al., 1995; Li and Hatton, 1997), facilitated by $\mathrm{Ca}^{2+}$ entry through NMDAR-gated channels. However, blocking glutamate transmission did not eliminate the effectiveness of choline to induce bursts. As shown in Figure $11 A, 1 \mathrm{~mm}$ choline induced phasic bursts in a putative VP neuron for which spontaneous phasic activity had been eliminated by blockade of the glutamate receptors. It seems from the data shown for Figure $11 A, C$ that activation of postsynaptic $\alpha 7 \mathrm{nAChRs,} \mathrm{with} \mathrm{their} \mathrm{ability} \mathrm{to} \mathrm{flux} \mathrm{large}$ amounts of $\mathrm{Ca}^{2+}$, can also trigger similar bursts independently of NMDAR activation. The selective $\alpha 7 \mathrm{nAChR}$ antagonist MLA was effective in blocking the choline-induced bursts (Fig. 11B).

Continuous firing patterns, typical of OX cells, are not dependent on ionotropic glutamate transmission in the slice (Fig. 11D).

\section{A. Control medium}
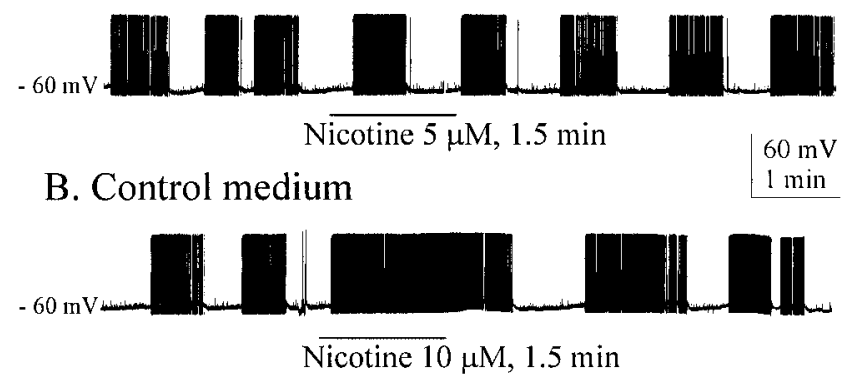

C. Control medium .

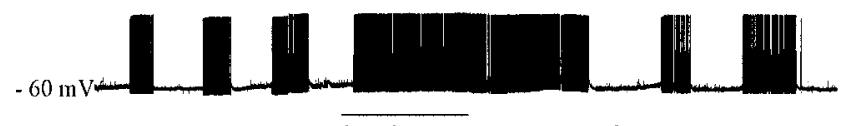

Nicotine $20 \mu \mathrm{M}, 1.5 \mathrm{~min}$

D. $\mathrm{Hi} \mathrm{Mg}^{2+} \&$ low $\mathrm{Ca}^{2+}$ medium

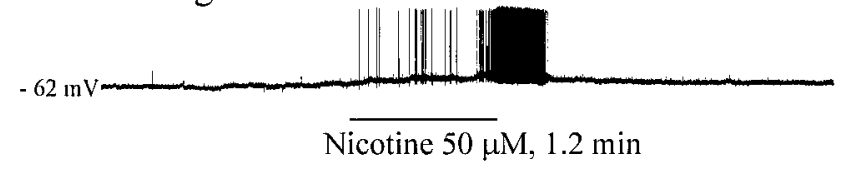

Figure 10. Effect of nicotine on phasically firing neurons. Although ineffective at $5 \mu \mathrm{M}(A)$, nicotine prolonged phasic bursts at $10 \mu \mathrm{M}(B)$ and $20 \mu \mathrm{M}(C)$. $D$, Blocking synaptic transmission typically eliminates phasic bursts in the SON, but nicotine application, presumably acting postsynaptically during this blockade, was able to evoke such bursts $(n=5)$.

Seconds after $1 \mathrm{~mm}$ choline was applied by bath, continuously firing (putative $\mathrm{OX}$ ) neurons showed membrane depolarizations with increased firing, but still in the continuous pattern. Similar responses to $1 \mathrm{~mm}$ choline were seen in all six cells tested, and in each case MLA blocked the effect, which was at least partially reversible (Fig. 11E,F). Again, the possibility that this excitation was at least in part attributable to activation of presynaptic $\alpha 7$ receptors cannot be ruled out.

\section{DISCUSSION}

This study is the first to demonstrate local circuit cholinergic activation of postsynaptic nAChRs in the hypothalamus. Both VP and $\mathrm{OX}$ neurons of the SON receive monosynaptic cholinergic inputs. Synaptic release of $\mathrm{ACh}$ from these inputs activates postsynaptic $\alpha 7 \mathrm{nAChRs}$ and possibly $\alpha 4 \beta 2 \mathrm{nAChRs}$ as well. Normally, this ACh release would also be expected to activate any presynaptic nAChRs in the area. Olfactory bulb inputs constitute one known source of glutamatergic presynaptic terminals here (Hatton and Yang, 1989) that might express $\alpha 7$ nAChRs. Selective activation of the postsynaptic $\alpha 7 \mathrm{nAChRs}$, either by selective agonists or with the $\alpha 4 \beta 2 \mathrm{nAChRs}$ antagonized, was sufficient to produce prolonged bursts of action potentials superimposed on plateau potentials in putative VP neurons. These potentials were similar in frequency and pattern to the potentials commonly produced by activation of NMDARs but occurred when NMDARs were blocked. Inhibition of both ionotropic glutamate transmission and $\mathrm{AChE}$ resulted in an increased frequency of EPSPs, suggesting that there was spontaneous presynaptic release of ACh in our horizontal slice preparations.

That these cholinergic inputs are monosynaptic, and not relayed to SON neurons via perinuclear interneurons, is evident from their consistently following high-frequency stimulation. Although the exact locations of the nicotinic cholinergic synapses on 


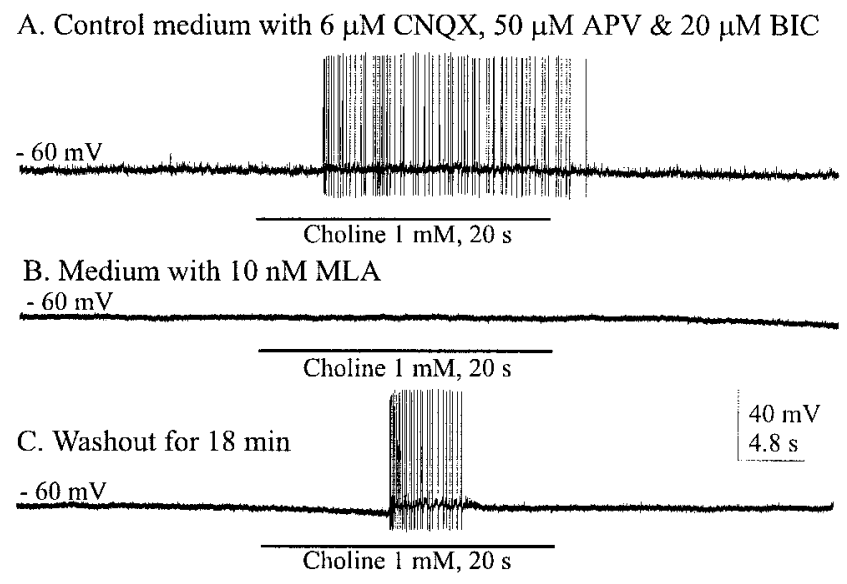

D. Control medium with $6 \mu \mathrm{M}$ CNQX, $50 \mu \mathrm{M}$ APV \& $20 \mu \mathrm{M}$ BIC
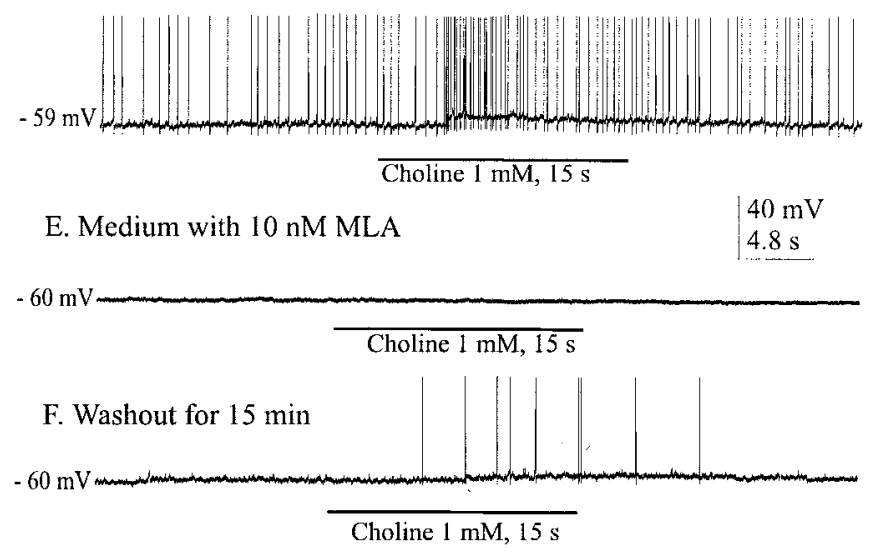

Figure 11. Effects of choline on phasically and continuously firing neurons. $A$, Choline applied by bath evoked bursts in neurons for which spontaneous phasic activity was silenced by glutamate receptor antagonists. $B$, MLA blocked these choline-induced responses, and washout reinstated them $(C)$. $D$, Continuous firing persists with glutamate receptors antagonized, and choline application was effective in enhancing firing rates. $E, F$, MLA reversibly blocked the choline-induced effect.

SON neurons are unknown at present, they are likely to be found on the distal dendrites, as is the case for most excitatory inputs. This would either be in the deep dendritic zone near the ventral glial lamina or in the more dorsal SON, where dendrites giving rise to axons are found (Hatton, 1990). It is in these regions that both cholinergic terminals and a high density of $\alpha$-bungarotoxin binding sites are seen (Meeker et al., 1988). Careful analyses using specific antibodies against the $\alpha 7$ - and $\alpha 4$-containing nAChRs are needed to localize these synapses further.

Results of activating these postsynaptic $\alpha 7 \mathrm{nAChRs}$ in the SON are generally consistent with those previously reported in hypothalamus (Zaninetti et al., 2000) and in hippocampal interneurons (Alkondon et al., 1998; Frazier et al., 1998). In all of these studies, including the present one, the nicotinic cholinergic responses were blocked by the selective $\alpha 7 \mathrm{nAChR}$ antagonists MLA and $\alpha$-bungarotoxin but not by the $\alpha 4$ nAChR-selective antagonist dihydro- $\beta$-erythroidine.

Zaninetti et al. (2000) found evidence for $\alpha 7 \mathrm{nAChRs}$ in all parts of the SON, suggesting that these receptors were on both OX and VP neurons. We have confirmed this, showing that continuously firing neurons for which spontaneous activity was not altered by blockade of ionotropic glutamate receptors (i.e.,
OX cells), as well as those for which spontaneous phasic patterns were blocked by the glutamate receptor antagonists (VP cells), were activated by synaptically released ACh. In both neuron types, exogenously applied ACh or its agonist, nicotine, were also effective in evoking the appropriate patterns of action potentials. Furthermore, we showed that these agonists were effective in the absence of synaptic transmission, confirming a postsynaptic site of action. $\mathrm{EC}_{50}$ values for $\mathrm{ACh}$ and nicotine obtained by Z aninetti et al. (2000) led them to suggest that there might be another subunit expressed together with the $\alpha 7$ in SON neurons. Our finding of incomplete desensitization to high-frequency activation of the cholinergic synapses is consistent with that suggestion. It seems to us, however, that both findings could be explained by the coexpression of $\alpha 7$ - and $\alpha 4$-containing receptors on these cells, because there is immunocytochemical evidence for both receptor types in the SON (del Toro et al., 1994; Shioda et al., 1997).

Like Zaninetti et al. (2000), we observed that ACh and nicotine required relatively high concentrations to evoke responses. This is consistent with the reported relatively low affinity of $\alpha 7$ nAChRs for these compounds. In contrast to the hippocampal $\alpha 7$ nAChRs studied by Frazier et al. (1998), who reported that $1 \mu \mathrm{M}$ nicotine desensitized the receptors and diminished the synaptic response, we did not observe desensitization to even 10 times higher concentrations of nicotine. Perhaps this is attributable to the lack of coexpression in the hippocampus of two receptor subtypes.

At low concentrations $\left(\mathrm{EC}_{50}, 1.6 \mathrm{~mm}\right)$, choline has been shown to be a full agonist at $\alpha 7$ - but not at $\alpha 4$-containing receptors (Alkondon et al., 1997). In agreement with this finding, our results showed that $1 \mathrm{~mm}$ choline applications were able to induce phasic firing bursts in the absence of synaptic transmission or to enhance the activity of continuously firing neurons. In addition, choline acted to increase the rate of the rising phase and amplitudes of evoked EPSPs in a manner and magnitude similar to that observed with inhibition of AChE by galanthamine. The former finding is consistent with the agonist role of choline, whereas the latter is consistent with findings showing that choline can inhibit AChE (Boyle et al., 1997; Stojan et al., 1999). Because choline is a metabolic product of ACh hydrolysis by $\mathrm{AChE}$, its selective action at $\alpha 7 \mathrm{nAChRs}$ suggests a rather complex interplay between these receptors and their transmitter system. This interpretation is based on the reasonable assumption that millimolar concentrations are attained in the synaptic region.

When contrasted with reports of certain previous studies, some of our findings present an apparent paradox. For example, it was found that antagonizing $\mathrm{AMPA}$ and $\mathrm{GABA}_{\mathrm{A}}$ receptors eliminated all stimulus-evoked (Gribkoff and Dudek, 1990) and miniature (Wuarin and Dudek, 1993) EPSPs and IPSPs recorded in SON slices. These authors concluded that, therefore, no fast synaptic responses could be mediated by ACh. The results presented here are antithetical to that conclusion. Indeed, we showed that fast EPSPs are mediated by synaptically released $\mathrm{ACh}$, and that blocking AMPA, NMDA, and $\mathrm{GABA}_{\mathrm{A}}$ receptor-mediated responses did not eliminate all spontaneously occurring EPSPs. In addition, additional blockade of $\mathrm{AChE}$, along with glutamate receptors, enhanced the frequency and amplitudes of these EPSPs. In our view, this discrepancy has a straightforward explanation. Those previous studies were done using coronal slices of hypothalamus containing the SON. Slices in this plane sever the axonal projections between the SON and areas that lie directly anterior (e.g., cholinergic neurons) or posterior (e.g., histaminergic neurons) to it. Whether the terminals of ACh axons that are 
severed from their cell bodies spontaneously release transmitter is unknown, but possibly they do not. Moreover, slicing in the coronal plane often damages the SON dendritic zone and ventral glial lamina, which are at the edge of the brain, where many cholinergic terminals and the most dense $\alpha$-bungarotoxin binding sites are found (Meeker et al., 1986, 1988). Therefore, spontaneous ACh-mediated EPSPs may not have been observable in coronal slices, although they were readily seen in ours, which were cut in a horizontal plane that left the cholinergic neurons and their axonal projections intact and did not damage the SON dendritic zone (Yang and Hatton, 1987).

What functional significance can we attach to these cholinergic inputs to OX and VP neurons in the SON, in particular, to their activation of nAChRs? The postsynaptic nAChRs studied here are likely to be among those involved in the long-recognized cholinergic control of VP release in response to dehydration (Pickford, 1939, 1947; Milton and Paterson, 1974; Sladek and Joynt, 1979). More recent advances in SON physiology, and the observation that both $\mathrm{OX}$ and VP neurons show $\alpha 7$ nAChRmediated postsynaptic responses, present several interesting possibilities. One of these, as conjectured by Zaninetti et al. (2000), is that the huge $\mathrm{Ca}^{2+}$ influx allowed by $\alpha 7 \mathrm{nAChR}$ activation could participate in the now well-documented dendritic release of peptide within the SON (Moos et al., 1984; Pow and Morris, 1989). It has also been shown that dendritic release of peptide can be functionally divorced from systemic release into the neurohypophysial blood circulation (Neumann et al., 1995), suggesting that SON neurons might be partitioned by different transmitter systems synapsing on different portions of the cell (e.g., ventrally vs dorsally projecting dendrites).

It has been noted (Broide and Leslie, 1999) that $\alpha 7 \mathrm{nAChRs}$ are inwardly rectifying, allowing cholinergically stimulated $\mathrm{Ca}^{2+}$ influx to occur through these postsynaptic receptors at resting or hyperpolarized membrane potentials. This would mean that $\mathrm{Ca}^{2+}$-dependent dendritic release of peptide in the SON could be evoked without the depolarization that accompanies activation of the outwardly rectifying NMDARs. Conversely, cholinergic activation of $\alpha 7 \mathrm{nAChRs}$ located presynaptically on nearby glutamate terminals could result in enhanced NMDAR activation. This reciprocal interplay between these two high $\mathrm{Ca}^{2+}$-fluxing receptors also involves their differential control by $\mathrm{Mg}^{2+}$. Extracellular $\mathrm{Mg}^{2+}$ blocks NMDAR-gated currents, whereas $\alpha 7$ nAChR-gated currents are blocked by intracellular $\mathrm{Mg}^{2+}$. Because NMDAR activation has been shown to result in elevated intracellular $\mathrm{Mg}^{2+}$, it appears that the presence of the two receptors in close proximity may be a mechanism for fine control of both $\mathrm{Ca}^{2+}$ influx and neuronal excitability.

\section{REFERENCES}

Alkondon M, Albuquerque E (1993) Diversity of nicotinic acetylcholine receptors in rat hippocampal neurons: I. Pharmacological and functional evidence for distinct structural subtypes. J Pharmacol Exp Ther 265:1455-1473.

Alkondon M, Reriera E, Cortes W, Maelicke A, Albuquerque E (1997) Choline is a selective agonist of alpha 7 nicotinic receptors in rat brain neurons. Eur J Neurosci 9:2734-2742.

Alkondon M, Pereira E, Albuquerque E (1998) $\alpha$-Bungarotoxin- and methllycaconitine-sensitive nicotinic receptors mediate fast synaptic transmission in interneurons of rat hippocampal slices. Brain Res 810:257-263.

Alkondon M, Pereira E, Eisenberg H, Albuquerque E (1999) Choline and selective antagonists identify two types of nicotinic acetylcholine receptors that modulate GABA release from CA1 interneurons in rat hippocampal slices. J Neurosci 19:2693-2705.

Bourque CW (1986) Calcium-dependent spike after-current induces burst firing in magnocellular neurosecretory cells. Neurosci Lett 70:204-209.

Boyle N, Talesa V, Giovannini E, Rosi G, Norton S (1997) Synthesis and study of thiocarbonate derivatives of choline as potential inhibitors of acetylcholinesterase. J Med Chem 40:3009-3013.

Broide R, Leslie F (1999) The $\alpha_{7}$ nicotinic receptor in neuronal plasticity. Mol Neurobiol 20:1-16.

Buisson B, Gopalakrishnan M, Arneric S, Sullivan J, Bertrand D (1996) Human 42 neuronal nicotinic acetylcholine receptor in HEK 293 cells: a patch-clamp study. J Neurosci 16:7880-7891.

del Toro E, Juiz J, Peng X, Lindstrom J, Criado M (1994) Immunocytochemical localization of the a7 subunit of the nicotinic acetylcholine receptor in the rat central nervous system. J Comp Neurol 349:325-342.

Frazier CJ, Buhler AV, Weiner JL, Dunwiddie TV (1998) Synaptic potentials mediated via $\alpha$-bungarotoxin-sensitive nicotinic acetylcholine receptors in rat hippocampal interneurons. J Neurosci 18:8228-8235.

Gribkoff VK, Dudek FE (1990) Effects of excitatory amino acid antagonists on synaptic responses of supraoptic neurons in slices of rat hypothalamus. J Neurophysiol 63:60-71.

Gribkoff VK, Christian EP, Robinson JH, Deadwyler SA, Dudek FE (1988) Cholinergic excitation of supraoptic neurons in hypothalamic slices of rat. Neuropharmacology 27:721-727.

Hatton GI (1982) Phasic bursting activity of rat paraventricular neurones in the absence of synaptic transmission. J Physiol (Lond) 327:273-284.

Hatton GI (1990) Emerging concepts of structure-function dynamics in adult brain: the hypothalamo-neurohypophysial system. Prog Neurobiol 34:437-504.

Hatton GI (1997) Function-related plasticity in hypothalamus. Annu Rev Neurosci 20:375-397.

Hatton GI (1999) Astroglial modulation of neurotransmitter/peptide release from the neurohypophysis: present status. J Chem Neuroanat 16:203-222.

Hatton GI, Yang QZ (1989) Supraoptic nucleus afferents from the main olfactory bulb. II. Intracellularly recorded responses to lateral olfactory tract stimulation on rat brain slices. Neuroscience 31:289-297.

Hatton GI, Doran AD, Salm AK, Tweedle CD (1980) Brain slice preparation: hypothalamus. Brain Res Bull 5:405-414.

Hatton GI, Ho YW, Mason WT (1983) Synaptic activation of phasic bursting in rat supraoptic nucleus neurones recorded in hypothalamic slices. J Physiol (Lond) 345:297-317.

Hu B, Bourque CW (1992) NMDA receptor-mediated rhythmic bursting activity in rat supraoptic nucleus neurones in vitro. J Physiol (Lond) 458:667-687.

Jacob M, Berg D (1983) The ultrastructural localization of $\alpha$-bungarotoxin binding sites in relation to synapses on chick ciliary ganglion neurons. J Neurosci 3:260-271.

Li ZH, Hatton GI (1997) Ca2 + release from internal stores: role in generating depolarizing after-potentials in rat supraoptic neurones. J Physiol (Lond) 498:339-350.

Li ZH, Decavel C, Hatton GI (1995) Calbindin- ${ }_{28 \mathrm{k}}$ : role in determining intrinsically generated firing patterns in rat supraoptic neurones. J Physiol (Lond) 488:601-608.

Mason WT, Ho YW, Eckenstein F, Hatton GI (1983) Mapping of cholinergic neurons associated with rat supraoptic nucleus: combined immunocytochemical and histochemical identification. Brain Res Bull 11:617-626.

Meeker RB, Michels KM, Libber MT, Hayward JN (1986) Characteristics and distribution of high- and low-affinity alpha bungarotoxin binding sites in the rat hypothalamus. J Neurosci 6:1866-1875.

Meeker RB, Swanson DJ, Hayward JN (1988) Local synaptic organization of cholinergic neurons in the basolateral hypothalamus. J Comp Neurol 276:157-168.

Milton AS, Paterson AT (1974) A microinjection study of the control of antidiuretic hormone release by the supraoptic nucleus of the hypothalamus in the cat. J Physiol (Lond) 241:607-628.

Moos F, Freund-Mercier MJ, Guerne Y, Guerne JM, Stoeckel ME Richard P (1984) Release of oxytocin and vasopressin by magnocellular nuclei in vitro: specific facilitatory effect of oxytocin on its own release. J Endocrinol 102:63-72.

Neumann I, Landgraf R, Bauce L, Pittman QJ (1995) Osmotic responsiveness and cross talk involving oxytocin, but not vasopressin or amino acids, between the supraoptic nuclei in virgin and lactating rats. J Neurosci 15:3408-3417.

Papke R, Bencherif M, Lippiello P (1996) An evaluation of neuronal nicotinic acetylcholine receptor activation by quaternary nitrogen compounds indicates that choline is selective for the alpha-7 subtype. Neurosci Lett 213:201-204.

Pickford M (1939) The inhibitory effects of acetylcholine on water diuresis in the dog, and its pituitary transmission. J Physiol (Lond) 95:226-238.

Pickford M (1947) The action of acetylcholine in the supraoptic nucleus of the chlorolosed dog. J Physiol (Lond) 106:264-270.

Pow DV, Morris JF (1989) Dendrites of magnocellular hypothalamic 
neurons release neurohypophysial peptides by exocytosis. Neuroscience 32:435-439.

Roerig B, Nelson D, Katz L (1997) Fast synaptic signaling by nicotinic acetylcholine and serotonin $5-\mathrm{HT}_{3}$ receptors in developing visual cortex. J Neurosci 17:8353-8362.

Sargent PB (1993) The diversity of nicotinic acetylcholine receptors. Annu Rev Neurosci 16:403-443.

Shioda S, Nakajo S, Hirabayashi T, Nakayama H, Matsuda K, Nakai Y (1997) Neuronal nicotinic acetylcholine receptor in the hypothalamus: morphological diversity and neuroendocrine regulations. Brain Res Mol Brain Res 47:45-54.

Sladek CD, Joynt RJ (1979) Cholinergic involvement in osmotic control of vasopressin release by the organ-cultured rat hypothalamoneurohypophyseal system. Endocrinology 105:367-371.

Stojan J, Marcel V, Fournier D (1999) Effect of tetramethylammonium, choline and adrophonium on insect acetylcholinesterase: test of a kinetic model. Chem Biol Interact 119-120:137-146.

Wuarin J-P, Dudek FE (1993) Patch-clamp analysis of spontaneous synaptic currents in supraoptic neuroendocrine cells of the rat hypothalamus. J Neurosci 13:2323-2331.

Yang QZ, Hatton GI (1987) Dye coupling among supraoptic nucleus neurons without dendritic damage: differential incidence in nursing mother and virgin rats. Brain Res Bull 19:559-565.

Zaninetti M, Blanchet C, Tribollet E, Bertrand D, Raggenbass M (2000) Magnocellular neurons of the rat supraoptic nucleus are endowed with functional nicotinic acetylcholine receptors. Neuroscience 95:319-323.

Zhang Z-W, Vijayaraghavan S, Berg DK (1994) Neuronal acetylcholine receptors that bind $\alpha$-bungarotoxin with high affinity function as ligandgated ion channels. Neuron 12:167-177. 